\title{
An Examination of Depressive Symptoms in Adolescents: The Relationship between Personality Traits and Perceived Social Support
}

\author{
Abdul Hanan Sami ${ }^{1}$, Naveeda Naveeda ${ }^{2}$ \\ Islamic International University Islamabad, Pakistan ${ }^{1}$ \\ Fatima Jinnah Women University Rawalpindi, Pakistan ${ }^{2}$ \\ Q2ahanans99@gmail.com*
}

Article Information:

Received April 17, 2020

Revised June 4, 2020

Accepted June 16, 2020

Keywords: adolescents; depressive symptoms; perceived social support; personality traits

\begin{abstract}
Present study aimed at investigating the association between personality traits, perceived social support and depressive symptoms in adolescents. Through convenient sampling, total 302 students (110 males and 192 females) were recruited from different universities of Rawalpindi and Islamabad. The age range of sample was 18-25 years. In present study, The Big Five Inventory- Short Version (BFI-S) (Gerlitz \& Schupp, 2005), The Multidimensional Scale of Perceived Social Support (MSPSS) (Zimet et al., 1988), and Depression, Anxiety and Stress Scale (DASS-21) (Lovibond \& Lovibond, 1995) were used to access personality traits, perceived social support and depressive symptoms. Findings of the present study showed a significant positive relationship between neuroticism and depressive symptoms. However, extraversion, conscientiousness and perceived social support showed significant negative association with depressive symptoms. According to regression analysis, neuroticism is a positive while, perceived social support is significant negative predictor of depressive symptoms in young adolescents. Furthermore, findings of present study may assist in identifying the personality traits at risk of experiencing depression.
\end{abstract}

\section{INTRODUCTION}

Depression is affecting individuals worldwide and it is considered as a leading health dilemma. Klein (1964) posited that people suffer from depression more than any other disease. According to DSM-5, depression can be characterized by prevalence of at least 5 symptoms including depressed mood, loss of interest in activities, sleep disturbance, fatigue, negative self-concept, inability to concentrate, psychomotor agitation and recurring thoughts of hurting self during two weeks (American Psychiatric Association, 2013). Depression is different from short duration mood changes that result as a consequence of daily stressors. It affects more than 300 million people worldwide according to WHO (2018) estimate. Depression is linked with physical symptom, fatigue, sleep trouble, psychomotor activity changes, and hunger changes are links with high depression. In addition, it also linked with two hormonal changes within the brain; serotonin and norepinephrine. It is believed that any imbalance between serotonin and norepinephrine leads to depression (Trivedi, 2004).

A vast body of studies has demonstrated the association between personality traits and depressive disorder such as major depressive disorder and depression (Clark et al., 1994; Elovainio et al., 2015; Kendler et al., 1993; Kotov et al., 2010; Ormel et al., 2013). In addition, at least six theoretical models have been explained in previous studies to enlighten

How to cite:

E-ISSN:

Published by:
Sami, A., \& Naveeda, N. (2021). An Examination of Depressive Symptoms in Adolescents: The Relationship of Personality Traits and Perceived Social Support. Is/amic Guidance and Counseling Journal, 4(1). https://doi.org/10.25217/igcj.v4i1.848 2614-1566

Institut Agama Islam Ma'arif NU (IAIMNU) Metro Lampung 
these associations and at least six theoretical models (Clark, 2005; Enns \& Cox, 1997; Klein et al., 2011; Krueger, \& Tackett, 2003; Watson \& Clark, 1995). In 2006, Matsudaira \& Kitamura (2006) ascertained that different personality traits are interrelated and their effects are independently associated to depression and anxiety.

Different models suggest the association between personality and depression including vulnerability model that suggests that personality traits or constructs predispose individuals and make them more vulnerable for developing disorder (Bagby et al., 2008). Pathoplasty model of personality-depression association suggests that personality traits affect the onset, course and severity of the depression. According to this model, neuroticism affects the severity and chronicity of depression but not development of the disorder (Bagby et al., 2008). In addition, complication model of personality-depression association suggests that personality traits affect the onset, course and severity of the depression. According to this model, neuroticism affects the severity and chronicity of depression but not development of the disorder (Bagby et al., 2008). Common-cause model suggest that depression and personality traits share common etiological factors. According to this model, serotonin functioning might be involved in personality traits and depression (Bagby et al., 2008).

According to Li et al. (2019) high neuroticism, low extraversion, and conscientiousness are significantly associated with depression. Among them, neuroticism is the chief construct which can predict the onset of depression. In addition, Jylha \& Isometsa (2006) posited strong relationship between neuroticism and depressive symptoms, and moderate association between introversion and depressive symptoms. Moreover, one study conducted to investigate the association between personality traits and psychological distress revealed significant positive association between neuroticism and psychological distress. While, findings depicted significant negative association between extraversion, openness, agreeableness, conscientiousness and psychological distress (Shaheen et al., 2014).

According to Cronkite and Moos (1995) social support is defined as availability of resources to an individual (as cited in Zixi \& Zhang, 2013). However, individual's perception of having social resources providing aid and care is known as perceived social support (Zixi, \& Zhang, 2013). According to Procidano and Heller (1983) the severity of psychological symptoms is majorly affected by the adequacy of social support (as cited in Lee, Dickson, Conley, \& Grayson, Holmbeck, 2014). Cobb (1976) identified three basic components of the social-support as succor, nurturance and affiliation, recognition and respect, group membership. Multiple studies have addressed the linkage between social support, perceived social support and depression (Najafabadi et al., 2015; Zixi, \& Zhang, 2013; Lee et al., 2014). Study conducted by Barnett and Gotlib (1988) aims to investigate the causal psychosocial factors associated with the depressive illness. Study identified six psychosocial factors as contributing in the illness were attributional styles, dysfunctional attitudes, personality, social support, marital status and coping styles. Results of review of studies suggested that marital distress and low social support plays role as etiological factors in depression.

The dynamics dynamics of social support and protection from depression through individual's life is highly encouraged to be observed (Gariepy et al., 2016). Literature suggests huge evidence regarding relationship between personality traits and depressive symptoms but contradicting findings has made the association between these two constructs more interesting to be investigated on target in sample diverse cultures.

\section{Rationale of the Current Study}

In present era, depression is a big trouble. Most of the population being affected is left undiagnosed and not given any proper attention which increases the chances of risk-taking behaviors and different mental health problems (Williams et al., 2017). Individual differences make an individual more and less oriented towards mental health issues. It is important to 
know the personality factors which are more susceptible towards depression in Pakistani culture. Therefore, the primary objective of present study is to identify the personality at risk of experiencing depression, so that it would be helpful in assisting such people.

As human is social animal and always remains in contact with people around him. It is a vivid point that social support provided to an individual in difficult decreases vulnerability of worry, stress and pain. Therefore, the aim of current study is also to discover relationship between perceived social support and depressive symptoms in adolescents to figure out the perception of adolescents regarding available social support.

\section{Hypotheses}

1. Neuroticism will have significant positive association with depressive symptoms in adolescents.

2. Personality traits such as extraversion, openness to experience, agreeableness and conscientiousness will show significant negative relationship with depressive symptoms.

3. Perceived social support will have significant negative association with depressive symptoms.

\section{METHODS}

\section{Participants}

In present study, three hundred and two adolescents $(\mathrm{N}=302)$ were recruited from multiple universities of Rawalpindi and Islamabad. The age of participants ranged from 18-25 years $(\mathrm{M}=22.54, \mathrm{SD}=3.54)$. Both males $36.4 \%(\mathrm{n}=110)$ and females $63.6 \%(\mathrm{n}=192)$ were part of the study. 65\% ( $\mathrm{n}=198)$ of participants belong to nuclear family system whereas $34.4 \%(n=104)$ belong to joint family system. $76.8 \%(n=232)$ were students, $13.9(n=42)$ were employed and $9.3 \%(\mathrm{n}=28)$ were unemployed.

\section{Instruments}

Following instruments were used to access study constructs.

\section{Big Five Inventory-Short Version (BFI-S)}

Gerlitz, and Schupp (2005) developed 15-item BFI-S to assess big five personality factors. Response answers were reduced from seven Likert scale to five-point Likert scale (1 $=$ strongly disagree to $5=$ strongly agree) (Lang et al. 2011). Conbach's alpha for personality traits such as neuroticism $=.52$, extraversion $=.60$, openness $=.55$, agreeableness $=.45$, conscientiousness $=.52$ (Brust, Hader, \& Hader, 2016).

\section{The Multidimensional Scale of Perceived Social Support (MSPSS)}

Zimet et al. (1988) developed MSPSS to examine individual's perception of social support. It consists of three subscales such as Family, Friends, and a Significant Other with four items each. Seven-point Likert scale was used for responses ranging from $1=$ strongly disagree to 7 = very strongly agree. Rizwan and Aftab (2009) reported Cronbach's alpha .89 for MSPSS.

\section{Depression, Anxiety, and Stress Scale (DASS-21)}

DASS-21 was developed by Lovibond and Lovibond (1995) to measure emotional states such as depression, anxiety and stress of an individual. Each subscale consists of seven items. Response options were made on 4-point Likert-type scale $(0=$ Did not apply to me at all, 3 = Applied to me very much or most of the time). Cronbach's alpha reported by Sinclair et al. (2012) for depression was .91. 


\section{Procedures}

By using convenient sampling technique data were collected from diverse colleges and universities of Rawalpindi and Islamabad. Informed consent was shared with respondents and were instructed about questionnaire booklet. They were assured about the confidentiality of provided information. Participants were thanked for their participation in study. Later on, the collected data was analyzed through statistical tool SPSS-21.

\section{RESULTS AND DISCUSSION Results}

The current study aimed at examining the association between personality traits, perceived social support and depressive symptoms in young adolescents. Descriptive statistics, correlation and regression analysis of study variables is as shown in Table 1. Results indicated satisfactory alpha reliabilities of scales and subscales.

Table 2. depicts relationship between personality traits, subscales of MSPSS and depression. According to results neuroticism has significant positive association with depression whereas extraversion, conscientiousness, perceived social support and its subscales have significant negative association with depressive symptoms. However, personality traits including openness and agreeableness have non-significant relationship with depressive symptoms.

Findings in Table 3. specify predictive role of neuroticism and perceived social support in relation to depression. Results indicate that neuroticism and perceived social support explained $21 \%$ variance in depressive symptoms among adolescents. According to findings neuroticism negatively and perceived social support positively predicts depressive symptoms.

\section{Discussion}

The objective of current study was to discover link between personality traits, perceived social support and depressive symptoms in adolescents. Different scales used to measure study constructs showed satisfactory internal consistency. Results of current study suggest that neuroticism has significant positive association with depressive symptoms. However, extraversion and perceived social support showed significant negative association with depressive symptoms among adolescents. Whereas, personality factors such as openness and agreeableness showed non-significant relationship with depressive symptoms.

In research field the association between personality traits and depression is a key topic (Klein et al., 2011). Personality trait such as neuroticism is considered as an important trait related to psychological disorders and physical problems (Lahey, 2009). Neurotic individuals are more inclined to negative emotions such as sadness, aggression, self-criticism, guilt and fear (Watson \& Clark, 1992). Research suggests that emotional stability is opposite to neuroticism in which individual experiences less mood swings and unpleasant emotions (John \& Srivastava, 1999). Consequently, it is obvious that personality trait (neuroticism) is strongly associated with depressive symptoms and anxiety, and in other words broadly with psychopathology (Jylha \& Isometsa, 2006; Clark \& Watson, 1991). Results of present study in lined with previous studies that neuroticism has significant positive association with symptoms of depression (Hakulinen et al., 2015; Yang et al., 2008). Literature also suggests that neuroticism has strong relationship with psychological distress (Engen 2008; Shaheen et al., 2014; Shirazi \& Ansari, 2012).

Findings of current study suggest that extraversion and conscientiousness has significant negative association with symptoms of depression. Results of earlier studies in line with present study (Bakker, Van der Zee, Lewig, \& Dollard, 2006; Hakulinen et al., 2015; Jylha \& Isometsa, 2006). Some of Personality traits including extraversion and conscientiousness are significantly decreases the likelihood of mental problems (Haslam, 
Table 1. Descriptive Statistics of Personality traits, MSPSS and DASS-21 ( $=302)$

\begin{tabular}{lllll}
\hline Variables & $\mathrm{k}$ & $\alpha$ & $\mathrm{M}$ & $\mathrm{SD}$ \\
\hline Neuroticism & 3 & .83 & 9.42 & 1.30 \\
Extraversion & 3 & .67 & 9.57 & 1.60 \\
Openness E & 3 & .68 & 11.22 & 2.22 \\
Agreeableness & 3 & .40 & 11.22 & 2.00 \\
Conscientiousness & 3 & .51 & 9.20 & 1.30 \\
MSPSS & 12 & .88 & 60.00 & 13.75 \\
SOS & 4 & .86 & 19.75 & 6.18 \\
Family Subscale & 4 & .85 & 20.41 & 5.48 \\
Friends Subscale & 4 & .81 & 19.34 & 5.16 \\
Depression & 7 & .73 & 6.97 & 3.99 \\
\hline
\end{tabular}

Note. Openness E = Openness to Experience, MSPSS $=$ Multidimensional Scale of Perceived Social Support, SOS = significant other subscale.

Table 2. Correlation between Personality traits, MSPSS, and Depressive Symptoms among Adolescents $(\mathrm{N}=302)$

\begin{tabular}{|c|c|c|c|c|c|c|c|c|c|c|c|}
\hline & Variables & 1 & 2 & 3 & 4 & 5 & 6 & 7 & 8 & 9 & 10 \\
\hline 1 & Neuroticism & 1 & -.04 & -.05 & .04 & .07 & -.03 & .05 & -.09 & -.03 & $.35^{* *}$ \\
\hline 2 & Extraversion & & 1 & $.13^{*}$ & $.20^{* * *}$ & $.16^{* *}$ & $.18^{* *}$ & $.15^{* *}$ & .08 & $.19^{* *}$ & $-.16^{* * *}$ \\
\hline 3 & OpennessE & & & 1 & $.17^{* * *}$ & $.25^{* *}$ & $.13^{*}$ & .08 & $.16^{* *}$ & .09 & -.10 \\
\hline 4 & Agreeable & & & & 1 & $.16^{* *}$ & .11 & $.12^{*}$ & .03 & $.13^{*}$ & -.07 \\
\hline 5 & Consc & & & & & 1 & $.11^{*}$ & .06 & $.14^{*}$ & .07 & $-.11^{*}$ \\
\hline 6 & MSPSS & & & & & & 1 & $.86^{* *}$ & $.86^{* *}$ & $.76^{* *}$ & $-.26^{* * *}$ \\
\hline 7 & SOS & & & & & & & 1 & $.70^{* *}$ & $.53^{* *}$ & $-.17^{* * *}$ \\
\hline 8 & Family S & & & & & & & & 1 & $.43^{* *}$ & $-.27^{* *}$ \\
\hline 9 & Friends S & & & & & & & & & 1 & $-.17^{* *}$ \\
\hline 10 & Depression & & & & & & & & & & 1 \\
\hline
\end{tabular}

Note. Openness $\mathrm{E}=$ Openness to experience, Agreeable $=$ Agreeableness, Consc $=$ Conscientiousness, MSPSS = Multidimensional Scale of Perceived Social Suport, SOS = Significant Other Subscale, Family $S=$ Family Subscale, Friends $S=$ Friends Subscale.

Table 3. Regression Analysis of Study Variables $(\mathrm{N}=302)$

\begin{tabular}{llll}
\hline Predictors & $B$ & $S . E$ & $B$ \\
\hline (Constant) & 6.16 & 2.53 & $.35^{* * *}$ \\
Neuroticism & 1.08 & .16 & -.08 \\
Extraversion & -.20 & .13 & -.00 \\
Openness E & -.01 & .09 & -.03 \\
Agreeableness & -.06 & .10 & -.09 \\
Conscientiousness & -.30 & .16 & $-.21^{* * *}$ \\
PSS & -.06 & .01 & \\
$R^{2}$ & .21 & & \\
$\Delta R^{2}$ & .19 & & \\
$F$ & $13.14^{* * *}$ & & \\
\hline
\end{tabular}

Note. $* p<.05, * * p<.01, * * * p<.001$, Openness $\mathrm{E}=$ Openness to experience, PSS $=$ Perceived Social Support.

Whelan, \& Bastian, 2009). Extraversion has significant concerns with wellbeing (Ozer \& Benet-Martinez, 2006), cognitive performance and (Smith \& Jones, 1992) social interactions (Eaton \& Funder, 2003). According to Widiger (2005), the risk and resilience of diverse psychopathology can be assessed by extraversion. Additionally, conscientiousness is associated with discipline and goal orientation. A conscientious person has a tendency to strive hard for planned goals and implementing on it (Petter, 2017).

The association between openness to experience and agreeableness was found nonsignificant with depressive symptoms in current study. The role of openness to experience and 
its relation to health has being studied but the findings are not consistent (Eldesouky, 2012). However, the relationship between openness to experience and depression was nonsignificant (Kotov et al., 2010; Klein et al., 2011). However, the results of present study contradict with earlier studies (Jylha \& Isometsa, 2006; Bakker et al., 2006; Chioqueta \& Stiles, 2005). Additionally, study conducted by (Bienvenu et al., 2004) showed slightly high mean of depressive patients on a facet of openness to experience. On contrary to literature, Ortiz and Gandara (2007) reported significant positive association between openness to experience and depression, depicting that association may be assessed when assessed with large sample size. As a good indicator of intellect openness to experience is considered as a good indicator of creativity (Eldesouky, 2012). Moreover, the non-significant association between agreeableness and depression is supported by previous researches (Junni, 2017; Leow \& Lynch, 2016).

In line with past studies, the results of current study depicted significant negative association between perceived social support and depressive symptoms (Baltaci, \& Karatas, 2015; Cohen \& Wills, 1985; Thoits, 1995). The ability of individual to become positive towards any stressful event makes individual less constraint which protects individual psychological well-being. Thus, an individual may become able to cope and control any kind of stressful life event. Additionally, past study conducted by Teoh and Rose (2001) illustrates that low social support is linked to depression, anxiety, low self-esteem, and other psychological problems. It is vivid that social support is an important factor involved in promoting better health and buffer against life stressors. Perceived social support acts as a protective factor as it decreases the perception of any situation as a threat and enhances the perception of resources in surrounding (Roohafza et al., 2014). Furthermore, social support facilitates intrapersonal skills, self-trust, responsibility, and self-control by three dimensions such as warmth, behavioral control and self-determination which decline the chances of psychological issues such as depression and anxiety (Oswald \& Suss, 1994).

In present study $19 \%$ of variation was contributed by neuroticism and perceived social support. The predictive role of neuroticism with depressive symptoms is reported by different study in research area (De Graaf et al., 2002; Hayward et al., 2000; Kendler et al., 2006; Ormel, et al., 2004). It is also found that neuroticism is a good marker of emotional disorders (Krueger et al., 1996). However, personality traits such as extraversion, openness to experience, agreeableness and conscientiousness were not found to be significant predictors of depressive symptoms in young adults.

\section{Limitations and Suggestions}

Along with strengths present study has also exhibits some limitations. Initially, data was collected with self-measuring inventories. However, structured interviews are recommended. Depressive symptoms can be over and under reported by the respondents so future studies should also consider interviews from family, friends and significant others. It is clear that personality traits cannot be properly accessed at single moment that is why longitudinal research design is suggested.

\section{Implications}

Present study will assist in identifying the personality traits associated with depressive symptoms in adolescents with respect to this specific culture. Additionally, findings of current study will help in designing the preventive strategies for individuals from experiencing mental health issues. It will also provide knowledge about the perception of adolescents regarding the provided social support. 


\section{CONCLUSIONS}

The findings of present study reported significant positive association between neuroticism and depressive symptoms. Moreover, significant negative association between was also found between extraversion, conscientiousness and perceived social support. According to results, neuroticism is significant positive and perceived social support is significant negative predictor of depressive symptoms.

\section{ACKNOWLEDGEMENTS}

In the name of Allah who is most merciful and beneficent. Alhamdulillah, Thanks to Allah. I also would like to thanks to my mentor my teacher and fatherly figure, Dr. Abdul Rashid for his confidence in me and support. He has always been there for me whenever I needed him. I would like to dedicate this work to him and would like say Thanks for all the things that he has done for me.

\section{AUTHOR CONTRIBUTIONS STATEMENT}

HS worked as the principal investigator for this research project. The study was designed, conceptualized and carried out by him. He had major contribution in devising theoretical framework and reviewing literature pertaining to the study. $\mathrm{N}$ has been an integral part of the whole process from brainstorming to writing her input has always been important. She played an important role in data collection and analysis. She worked diligently and with interest and integrity. Both authors (HS \& N) read and approved the final manuscript.

\section{REFERENCES}

American Psychiatric Association. (2013). Diagnostic and statistical manual of mental disorders (DSM-5®). American Psychiatric Pub. Google Scholar

Bagby, R. M., Quilty, L. C., \& Ryder, A. C. (2008). Personality and depression. The Canadian Journal of Psychiatry, 53(1), 14-25. https://doi.org/10.1177/070674370805300104

Bakker, A. B., Van Der Zee, K. I., Lewig, K. A., \& Dollard, M. F. (2006). The relationship between the big five personality factors and burnout: A study among volunteer counselors. The Journal of Social Psychology, 146(1), 31-50. https://doi.org/10.3200/socp.146.1.31-50

Baltaci, H. Ş., \& Karataş, Z., (2015). Perceived social support, depression and life satisfaction as the predictor of the resilience of secondary school students: The case of Burdur. Eurasian Journal of Educational Research, 15(60), 111-130. https://doi.org/10.14689/ejer.2015.60.7

Barnett, P. A., \& Gotlib, I. H. (1988). Dysfunctional attitudes and psychosocial stress: The differential prediction of future psychological symptomatology. Motivation and Emotion, 12(3), 251-270. https://doi.org/10.1007/BF00993114

Bienvenu, O. J., Samuels, J. F., Costa, P. T., Reti, I. M., Eaton, W. W., \& Nestadt, G. (2004). Anxiety and depressive disorders and the five-factor model of personality: A higher-and lower-order personality trait investigation in a community sample. Depression and Anxiety, 20(2), 92-97. https://doi.org/10.1002/da.20026

Brust, O. A., Häder, S., \& Häder, M. (2016). Is the Short Version of the Big Five Inventory (BFI-S) Applicable for Use in Telephone Surveys?. Journal of Official Statistics, 32(3), 601-618. https://doi.org/10.1515/jos-2016-0031

Carrasco Ortiz, M. A., \& Barrio Gándara, M. V. D. (2007). Temperamental and personality variables in child and adolescent depressive symptomatology. Psicothema, 19(1). Google Scholar 
Chioqueta, A. P., \& Stiles, T. C. (2005). Personality traits and the development of depression, hopelessness, and suicide ideation. Personality and Individual Differences, 38(6), 12831291. https://doi.org/10.1016/j.paid.2004.08.010

Clark, L. A. (2005). Temperament as a unifying basis for personality and psychopathology. Journal of Abnormal Psychology, 114(4), 505. https://doi.org/10.1037/0021-843x.114.4.505

Clark, L. A., \& Watson, D. (1991). General affective dispositions in physical and psychological health. Handbook of Social and Clinical Psychology, 12, 221-245. Google Scholar

Cobb, S. (1976). Social support as a moderator of life stress. Psychosomatic Medicine, 38(5), 300-314. https://doi.org/10.1097/00006842-197609000-00003

Cohen, S., \& Willis, T. A. (1985). Stress, social support, and buffering hypothesis. Psychological Bulletin, 98, 310-357. https://doi.org/10.1037/0033-2909.98.2.310

Cronkite, R. C., \& Moos, R. H. (1995). Life context, coping process, and depression. In E. Beckham \& B. Leber (Eds.), Handbook of Depression (2nd ed., pp. 569-587). New York: Guilford. Google Scholar

De Graaf, R., Bijl, R. V., Ravelli, A., Smit, F., \& Vollebergh, W. A. M. (2002). Predictors of first incidence of DSM-III-R psychiatric disorders in the general population: findings from the Netherlands Mental Health Survey and Incidence Study. Acta Psychiatrica Scandinavica, 106(4), 303-313. https://doi.org/10.1034/j.1600-0447.2002.01397.x

Eaton, L. G., \& Funder, D. C. (2003). The creation and consequences of the social world: An interactional analysis of extraversion. European Journal of Personality, 17(5), 375-395. https://doi.org/10.1002/per.477

Eldesouky, L. (2012). Openness to experience and health: A review of the literature. The Yale Review of Undergraduate Research in Psychology, 5, 24-42. Google Scholar

Elovainio, M., Jokela, M., Rosenström, T., Pulkki-Råbäck, L., Hakulinen, C., Josefsson, K., ... \& Keltikangas-Järvinen, L. (2015). Temperament and depressive symptoms: What is the direction of the association? Journal of Affective Disorders, 170, 203-212. https://doi.org/10.1016/j.jad.2014.08.040

Engen, G. (2008). The psychosocial predictors of psychological distress and life satisfaction in a cohort of Norwegian students (Master's thesis). University of Oslo. Google Scholar

Enns, M. W., \& Cox, B. J. (1997). Personality dimensions and depression: review and commentary. The Canadian Journal of Psychiatry, 42(3), 274-284. https://doi.org/10.1177\%2F070674379704200305

Funder, D. C. (2001). Personality. Annual Review of Psychology, 52, 197-221. https://doi.org/10.1146/annurev.psych.52.1.197

Gariepy, G., Honkaniemi, H., \& Quesnel-Vallee, A. (2016). Social support and protection from depression: systematic review of current findings in Western countries. The British Journal of Psychiatry, 209(4), 284-293. https://doi.org/10.1192/bjp.bp.115.169094

Gerlitz, J. Y, \& Schupp, J. (2005). To survey the Big Five-based personality traits in the SOEP. DIW Research Notes, 4, 2005. Google Scholar

Hakulinen, C., Elovainio, M., Pulkki-Råback, L., Virtanen, M., Kivimäki, M., \& Jokela, M. (2015). Personality and depressive symptoms: Individual participant meta-analysis of 10 cohort studies. Depression and Anxiety, 32(7), 461-470. https://doi.org/10.1002/da.22376

Haslam, N., Whelan, J., \& Bastian, B. (2009). Big Five traits mediate associations between values and subjective well-being. Personality and Individual Differences, 46(1), 40-42. https://doi.org/10.1016/j.paid.2008.09.001 
Hayward, C., Killen, J. D., Kraemer, H. C., \& Taylor, C. B. (2000). Predictors of panic attacks in adolescence. Journal of the American Academy of Child \& Adolescent Psychiatry, 39, 207-214. https://doi.org/10.1097/00004583-200002000-00021

Hirschfeld, R. M. A., Klerman, G. L., Clayton, P. J., \& Keller, M. B. (1983). Personality and depression: Empirical findings. Archives of General Psychiatry, 40, 993-998. https://doi.org/10.1001/archpsyc.1983.01790080075010

Hobfoll, S. E., \& Vaux, A. (1993). Social support: Social resources and social context. In L. Goldberger \& S. Breznitz (Eds.), Handbook of Stress (pp. 685-705). New York: Free Press. Google Scholar

Izard, C. E., Libero, D. Z., Putnam, P., \& Haynes, O. M. (1993). Stability of emotion experiences and their relations to traits of personality. Journal of Personality and Social Psychology, 64(5), 847. Google Scholar

John, O. P., \& Srivastava, S. (1999). The Big Five trait taxonomy: History, measurement, and theoretical perspectives. Handbook of personality: Theory and Research, 2, 102-138.

Jonassaint, CR. et al. (2007). Facets of Openness predict Mortality in Patients with Cardiac Disease. Psychosomatic Medicine, 69, 319-322. Google Scholar

Junni, J. (2017). Personality and Depression: Relationship between Five-Factor Personality Traits and Depressive Symptoms. https://helda.helsinki.fi/handle/10138/181438

Jylha, P., \& Isometsa, E. (2006). The relationship of neuroticism and extraversion to symptoms of anxiety and depression in the general population. Depression and anxiety, 23(5), 281-289. https://doi.org/10.1002/da.20167

Kendler, K. S., Gatz, M., Gardner, C. O., \& Pedersen, N. L. (2006). Personality and major depression: a Swedish longitudinal, population-based twin study. Archives of General Psychiatry, 63, 1113-1120. https://doi.org/10.1001/archpsyc.63.10.1113

Kendler, K. S., Neale, M. C., Kessler, R. C., Heath, A. C., \& Eaves, L. J. (1993). A longitudinal twin study of personality and major depression in women. Archives of General Psychiatry, 50(11), 853-862. Google Scholar

Klein, D. F. (1964). Delineation of two drug-responsive anxiety syndromes. Psychopharmacology, 5(6), 397-408. https://doi.org/10.1007/BF02193476

Klein, D. N., Kotov, R., \& Bufferd, S. J. (2011). Personality and depression: explanatory models and review of the evidence. Annual Review of Clinical Psychology, 7, 269-295. https://doi.org/10.1146/annurev-clinpsy-032210-104540

Kotov, R., Gamez, W., Schmidt, F., \& Watson, D. (2010). Linking "big” personality traits to anxiety, depressive, and substance use disorders: a meta-analysis. Psychological Bulletin, 136(5), 768. https://psycnet.apa.org/doi/10.1037/a0020327

Krueger, R. F., \& Tackett, J. L. (2003). Personality and psychopathology: Working toward the bigger picture. Journal of Personality Disorders, 17(2: Special issue), 109-128. https://doi.org/10.1521/pedi.17.2.109.23986

Krueger, R. F., Caspi, A., Moffitt, T. E., Silva, P. A., \& McGee, R. (1996). Personality traits are differentially linked to mental disorders: A multi trait-multi diagnosis study of an adolescent birth cohort. Journal of Abnormal Psychology, 105, 299-312. https://doi.org/10.1037/0021-843X.105.3.299

Lahey, B. B. (2009). Public health significance of neuroticism. American Psychologist, 64(4), 241. https://doi.org/10.1037/a0015309

Lang, F. R., John, D., Lüdtke, O., Schupp, J., \& Wagner, G. G. (2011). Short assessment of the Big Five: Robust across survey methods except telephone interviewing. Behavior Research Methods, 43(2), 548-567. https://doi.org/10.3758/s13428-011-0066-z

Lee, C., Dickson, D. A., Conley, C. S., \& Holmbeck, G. N. (2014). A closer look at selfesteem, perceived social support, and coping strategy: A prospective study of depressive 
symptomatology across the transition to college. Journal of Social and Clinical Psychology, 33(6), 560-585. https://doi.org/10.1521/jscp.2014.33.6.560

Leow, K., Lee, M., \& Lynch, M. F. (2016). Big five personality and depressive symptoms: A Self-Determination Theory perspective on students' positive relationships with others. VISTAS. Google Scholar

Li, Y., Wei, D. T., Sun, J. Z., Meng, J., Ren, Z. T., He, L., ... \& Qiu, J. (2019). Personality and depression: A review of theory model and behavior and neural mechanism. Sheng li xue bao:[Acta physiologica Sinica], 71(1), 163-172. Google Scholar

Lovibond, P. F., \& Lovibond, S. H. (1995). The structure of negative emotional states: Comparison of the Depression Anxiety Stress Scales (DASS) with the Beck Depression and Anxiety Inventories. Behavior Research and Therapy,33(3), 335-343. https://doi.org/10.1016/0005-7967(94)00075-U

Matsudaira T., \& Kitamura, T., (2006). Personality Traits as Risk Factors of Depression and Anxiety Among Japanese Students. Journal of Clinical Psychology, 62(1), 97-109. https://doi.org/10.1002/jclp.20215

Najafabadi, M. T., Kalhori, H., Javadifar, N., \& Haghighizadeh, M. H. (2015). Association between perceived social support and depression in postmenopausal women. Jundishapur Journal of Chronic Disease Care, 4(4). https://dx.doi.org/10.17795/jjcdc-30126

Ormel, J., Jeronimus, B. F., Kotov, R., Riese, H., Bos, E. H., Hankin, B., ... \& Oldehinkel, A. J. (2013). Neuroticism and common mental disorders: meaning and utility of a complex relationship. Clinical Psychology Review, 33(5), 686-697. https://doi.org/10.1016/j.cpr.2013.04.003

Ormel, J., Oldehinkel, A. J., \& Vollebergh, W. (2004). Vulnerability before, during, and after a major depressive episode: a 3-wave population-based study. Archives of General Psychiatry, 61, 990-996. https://doi.org/10.1001/archpsyc.61.10.990

Oswald, H., \& Süss, K. U. (1994). The influence of parents and peers on misconduct at school: Simultaneous and synergistic effects. Google Scholar

Ozer, D. J., \& Benet-Martinez, V. (2006). Personality and the prediction of consequential outcomes. Annu. Rev. Psychol., 57, 401-421. https://doi.org/10.1146/annurev.psych.57.102904.190127

Petter, O., (2017). Conscientious extroverts are less at risk of depression and anxiety, claims study. https://www.independent.co.uk/life-style/extroverts-depression-anxiety-less-riskmental-health-conscientious-study-a8086481.html

Rizwan, M., \& Aftab, S. (2009). Psychometric properties of the multidimensional scale of perceived social support in Pakistani young adults. Pakistan Journal of Psychology, 40(1). Google Scholar

Roohafza, H. R., Afshar, H., Keshteli, A. H., Mohammadi, N., Feizi, A., Taslimi, M., \& Adibi, P. (2014). What's the role of perceived social support and coping styles in depression and anxiety?. Journal of research in medical sciences: the official journal of Isfahan University of Medical Sciences, 19(10), 944. Google Scholar

Shaheen, F., Jahan, M., \& Shaheen, S. (2014). Role of personality factors in experiencing psychological distress among adolescents. Journal of Education and Psychological Research, 3(1), 14-20. Google Scholar

Shirazi, M., Khan, M. A., \& Ansari, M. F. (2012). Mental health in relation to personality characteristics among professional and non-professional students. Journal of Arts, Science and Commerce, 3(1). Google Scholar

Sinclair, S. J., Siefert, C. J., Slavin-Mulford, J. M., Stein, M. B., Renna, M., \& Blais, M. A. (2012). Psychometric evaluation and normative data for the depression, anxiety, and 
stress scales-21 (DASS-21) in a nonclinical sample of US adults. Evaluation \& the Health Professions, 35(3), 259-279. https://doi.org/10.1177/0163278711424282

Smith, A. P., \& Jones, D. M. (1992). Handbook of human performance. Vol. 3, State and trait. Academic Press. Google Scholar

Teoh, H. J., \& Rose, P. (2001). Child mental health: Integrating Malaysian needs with international experiences. Mental Health in Malaysia, 103-121. Google Scholar

Thoits, P. A. (1995). Stress, coping, and social support processes: Where are we? What next?. Journal of Health and Social Behavior, 53-79. Google Scholar

Trivedi, M. H. (2004). The Link between Depression and Physical Symptoms. Primary Care Companion to the Journal of Clinical Psychiatry, 6(suppl 1), 12-16. Google Scholar

Watson, D., \& Clark, L. A. (1992). On traits and temperament: General and specific factors of emotional experience and their relation to the five-factor model. Journal of Personality, 60(2), 441-476. https://doi.org/10.1111/j.1467-6494.1992.tb00980.x

Watson, D., \& Clark, L. A. (1995). Depression and the melancholic temperament. European Journal of Personality, 9(5), 351-366.

WHO. (2018). Depression. https://who.int/news-room/fact-sheets/detail/depression

Widiger, T. A. (2005). Five factor model of personality disorder: Integrating science and practice. Journal of Research in Personality, 39 (1), 67-83. https://doi.org/10.1016/j.jrp.2004.09.010

Williams, S. Z., Chung, G. S., \& Muennig, P. A. (2017). Undiagnosed depression: A community diagnosis. SSM-population health, 3, 633-638. https://doi.org/10.1016/j.ssmph.2017.07.012

Yang, H. J., Chiu, Y. J., Soong, W. T., \& Chen, W. J. (2008). The roles of personality traits and negative life events on the episodes of depressive symptoms in non-referred adolescents: a 1-year follow-up study. Journal of Adolescent Health, 42(4), 378-385. https://doi.org/10.1016/j.jadohealth.2007.09.017

Zimet, G. D., Dahlem, N. W., Zimet, S. G., \& Farley, G. K. (1988). The multidimensional scale of perceived social support. Journal of Personality Assessment, 52, 30-41. Google Scholar

Zixi, W., \& Zhang, Y., (2013). Acculturative Stress, Perceived Social Support and Depression Among Chinese International Students. Master's Level Graduate Research Conference. 185. Google Scholar

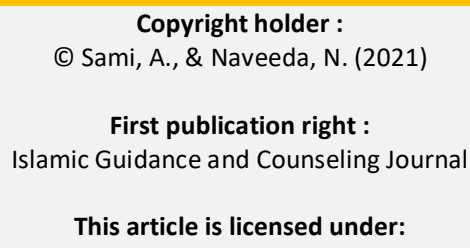

